\title{
CCSI Technology Readiness Levels Likelihood Model (TRL-LM) User's Guide
}

\author{
DW Engel
}

AC Dalton

C Sivaramakrishnan

C Lansing

March 2013

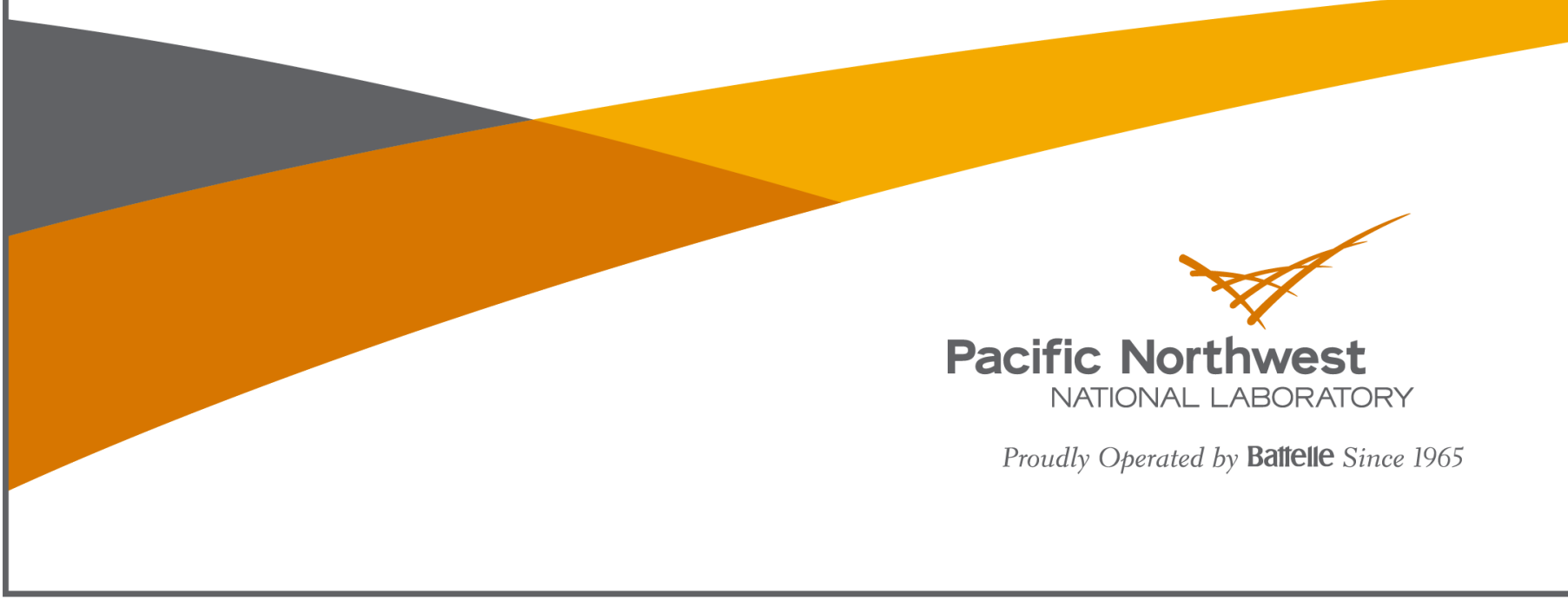




\title{
DISCLAIMER
}

This report was prepared as an account of work sponsored by an agency of the United States Government. Neither the United States Government nor any agency thereof, nor Battelle Memorial Institute, nor any of their employees, makes any warranty, express or implied, or assumes any legal liability or responsibility for the accuracy, completeness, or usefulness of any information, apparatus, product, or process disclosed, or represents that its use would not infringe privately owned rights. Reference herein to any specific commercial product, process, or service by trade name, trademark, manufacturer, or otherwise does not necessarily constitute or imply its endorsement, recommendation, or favoring by the United States Government or any agency thereof, or Battelle Memorial Institute. The views and opinions of authors expressed herein do not necessarily state or reflect those of the United States Government or any agency thereof.

\author{
PACIFIC NORTHWEST NATIONAL LABORATORY \\ operated by \\ BATTELLE \\ for the \\ UNITED STATES DEPARTMENT OF ENERGY \\ under Contract DE-AC05-76RL01830
}

Printed in the United States of America
Available to DOE and DOE contractors from the Office of Scientific and Technical Information,
P.O. Box 62, Oak Ridge, TN 37831-0062;
ph: (865) 576-8401
fax: $(865)$ 576-5728
email: reports@adonis.osti.gov

\begin{abstract}
Available to the public from the National Technical Information Service, U.S. Department of Commerce, 5285 Port Royal Rd., Springfield, VA 22161 ph: (800) 553-6847 fax: $(703) 605-6900$ email: orders@ntis.fedworld.gov online ordering: http://www.ntis.gov/ordering.htm
\end{abstract}

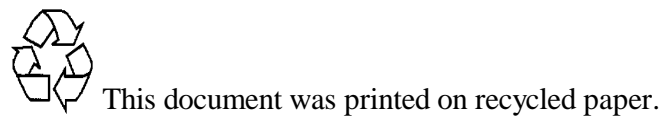




\title{
CCSI Technology Readiness Levels Likelihood Model (TRL-LM) User's Guide
}

\author{
DW Engel \\ AC Dalton \\ C Sivaramakrishnan \\ C Lansing
}

March 2013

Prepared for

the U.S. Department of Energy

under Contract DE-AC05-76RL01830

Pacific Northwest National Laboratory

Richland, Washington 99352 


\section{Request and Create a New User Account}

1.1. After successful installation, the user will need an account in order to use the TRL-LM. To do so, go to CCSI homepage, and click on the "Request an Account" tab.

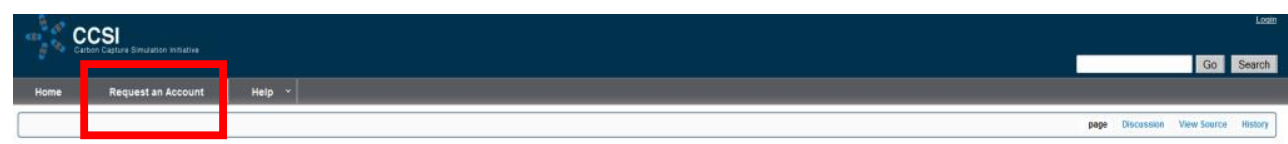

CCSI Home

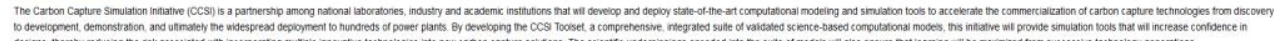

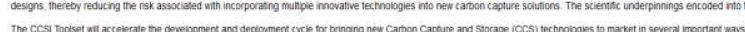

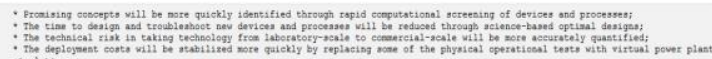

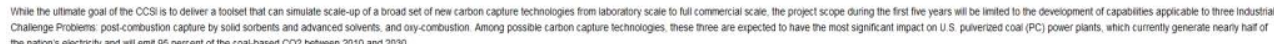

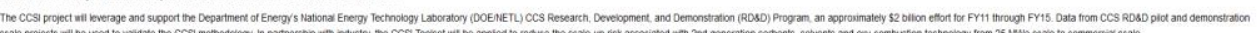

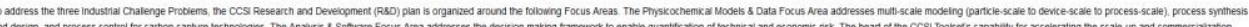

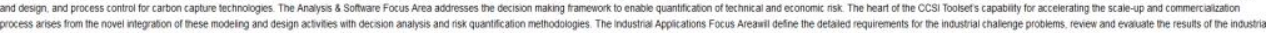

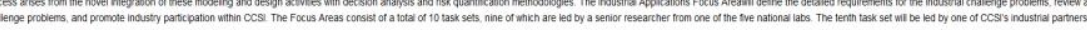

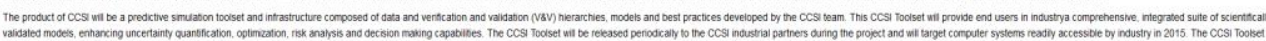

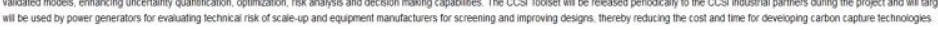

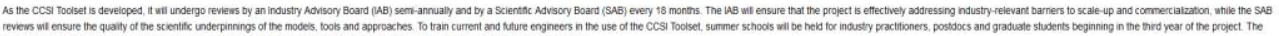

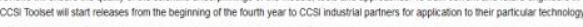

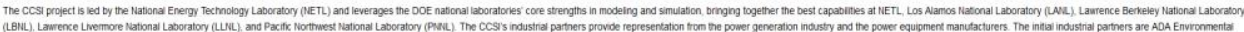

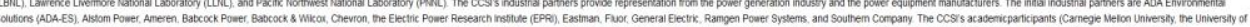

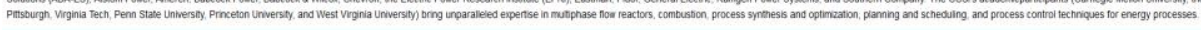

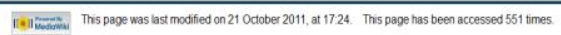

\subsection{Create an Account}

Follow the instructions to request an account by entering all the necessary information. Make sure to read the terms of service and check the appropriate box before requesting an account.

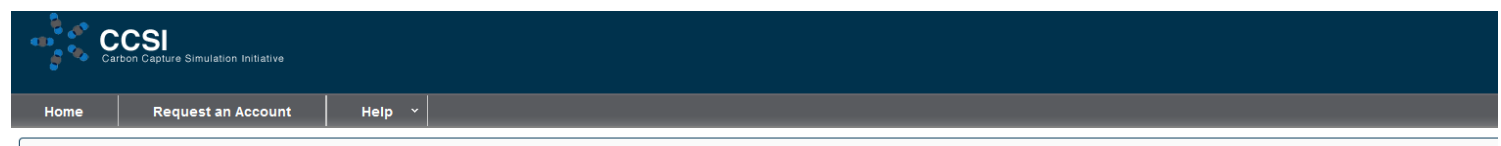

\section{Special:RequestAccount}

complete and submit the following form to request a user account

Make sure that you first read the Terms of Service before requesting an account.

Once the account is approved, you will be e-mailed a notification message and the account will be usable at login.

-User account-

Your e-mail address will be sent a confirmation message once this request is submitted. Please respond by clicking on the confirmation link provided by the e-mail. Also, your password will be e-mailed to you when your account is created.

Username

E-mall adoress:

- Personal information

Your biography will be set as the default content for your userpage. Try to include any credentials. Make sure you are comfortable publishing such information. Your name can be changed via your preferences

Real name:

Personal biography:

have read and agree to abide by the Terms of Service of CCSI. The name I have specified under "Real name" is in fact my own real name 
1.3. The user will receive an email confirmation and will be required to activate the account by clicking on the link in the email. A new page will appear; click on the "Request an Account" tab.

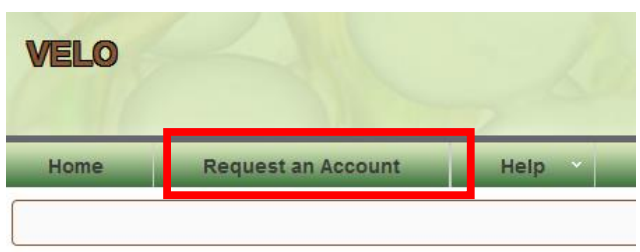

\section{Login required}

You must log in to view other pages.

Return to GS3 Home.

1.4. Log in with the user name and password. Be sure to check the box next to "I agree to the disclaimer's terms and conditions."

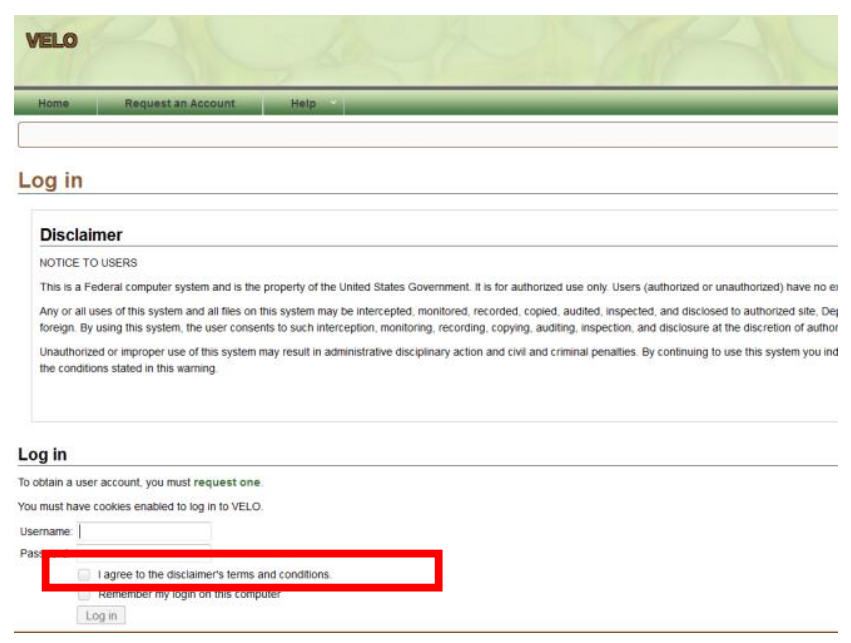

1.5. The screen will indicate that the user's e-mail address has been confirmed. The user can proceed to CCSI home page and navigate to TRL-LM.

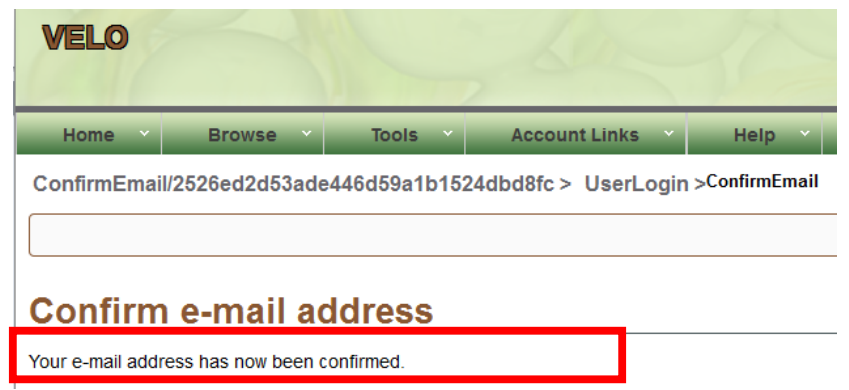




\section{TRL-LM: Questionnaire and Results}

2.1. To access TRL-LM, go to CCSI homepage and log in by clicking on the "Login" button in the upper right corner of the page.

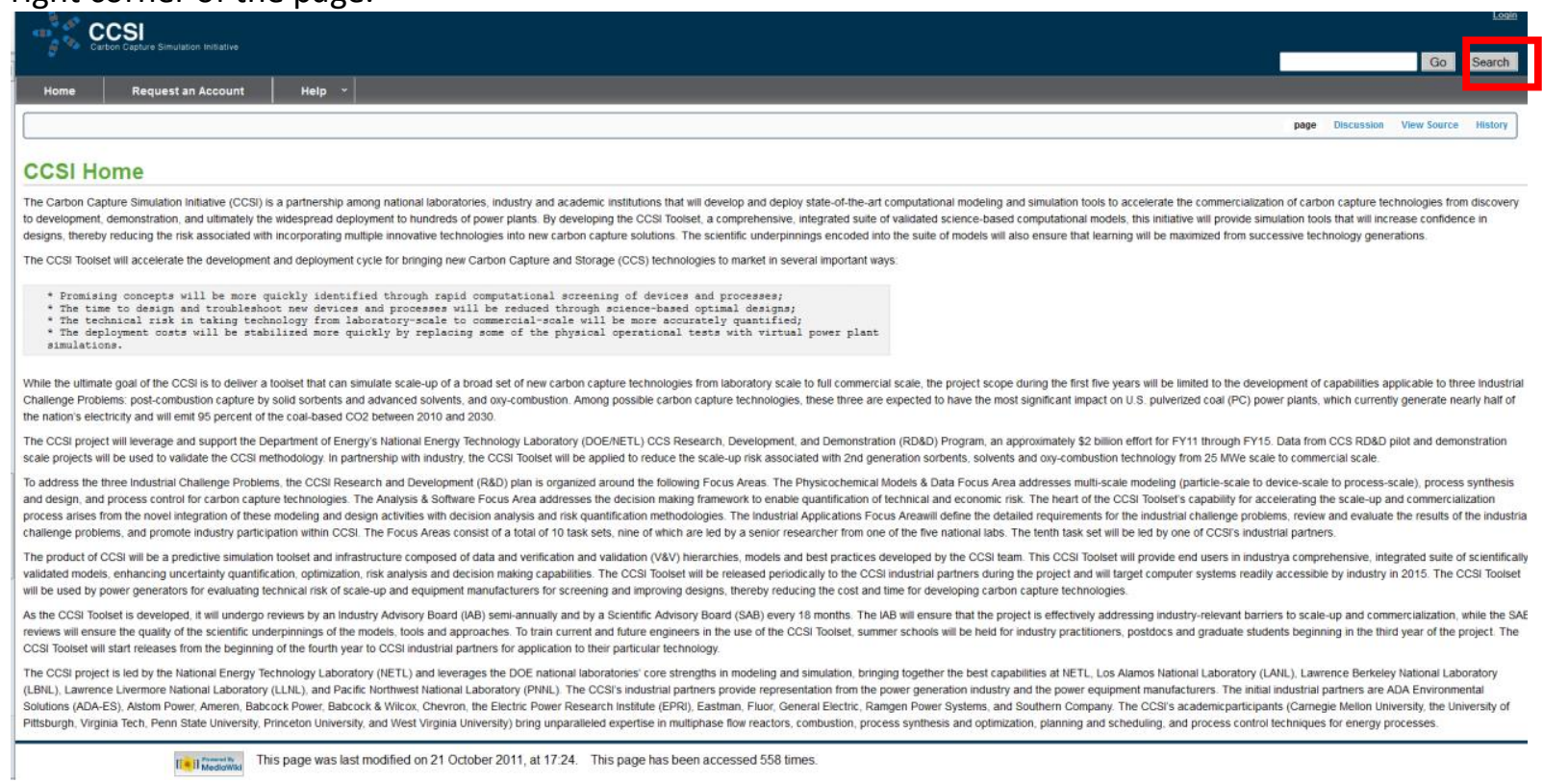

2.2. On the login page, enter the user name and password. Make sure to read and agree to the disclaimer's terms and conditions.

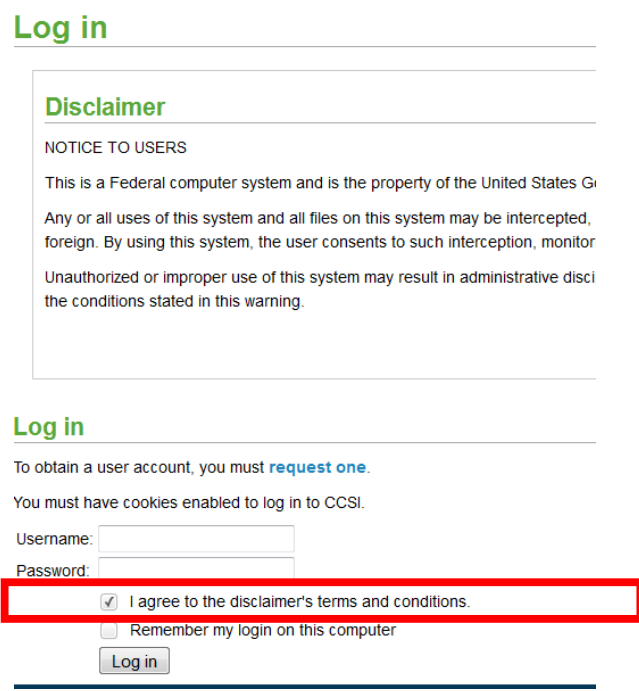

2.3. Once logged in, hover the mouse over the "Home" tab, and select "Technologies" from the dropdown list to navigate to the TRL-LM page. 


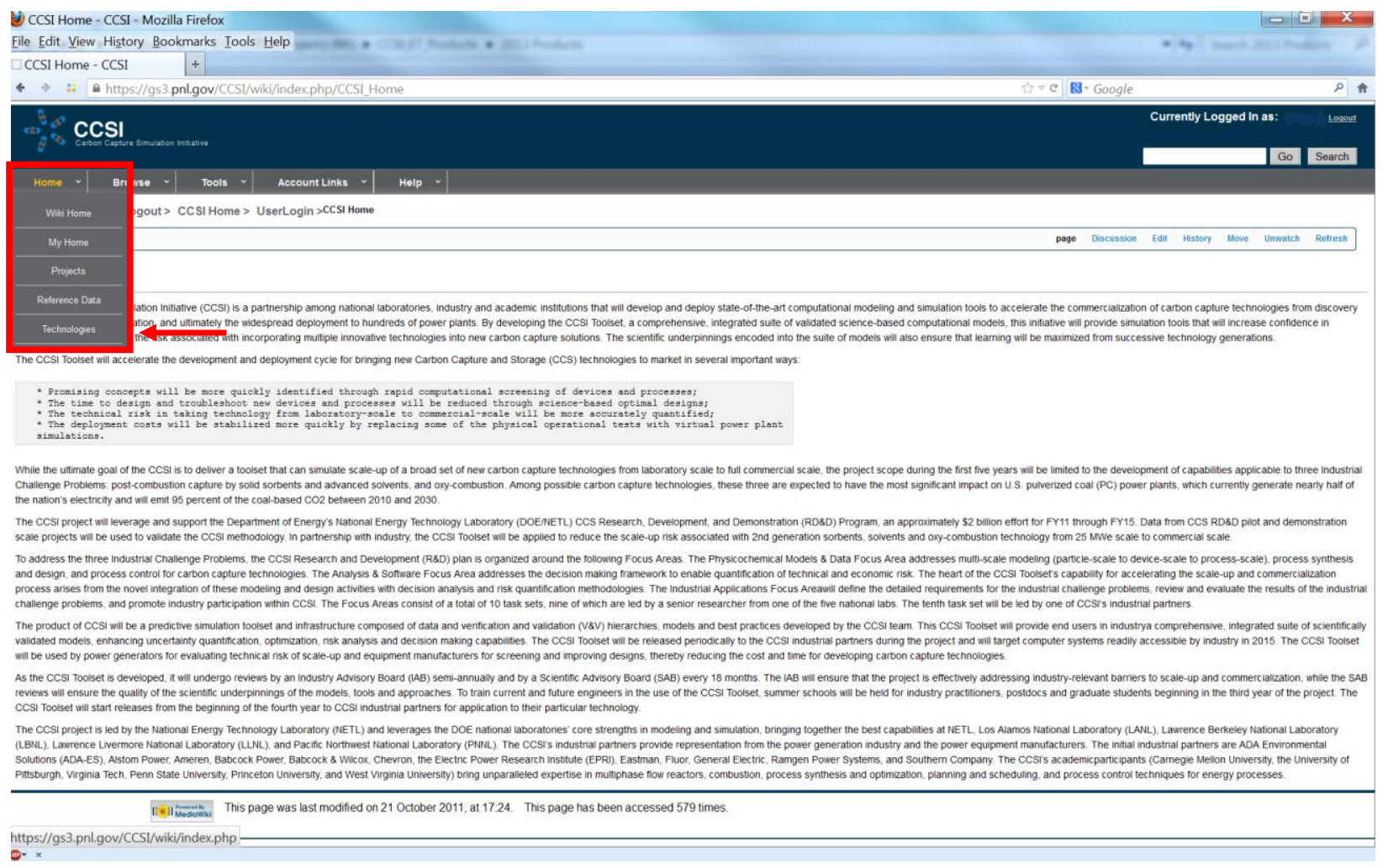

2.4. Locate "File Manager" on the left side of the screen. Under the file manager, two items are listed: TRL_Template.csv and SolidSorbent. The csv template contains all the questions and descriptions that will be displayed in the TRL questionnaire, and it sets the default format for the questionnaire. Solid Sorbent is a technology for which readiness assessment is sought. The user can modify the questionnaire (see Section 3.1), and add more technologies for TRL assessment (see Section 3.2).

\begin{tabular}{l|l|l|l|l|l|}
\hline \\
Home $~$
\end{tabular}

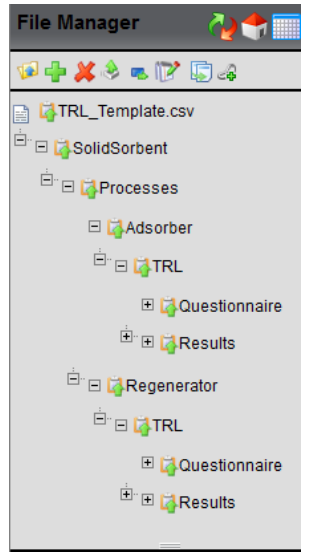

2.5. Click on the plus symbol next to "Solid Sorbent" to unfold and view the TRL-LM file directory structure. For each technology, there is a "Processes" folder to accommodate one or more processes within a technology. For example, for the solid sorbent based carbon capture technology, we focus on two processes: adsorber and regenerator. See Section 3.2 for instructions on how to add more processes to a technology. Within each process, there is a technology readiness level (TRL) folder containing a Questionnaire folder, and a Results folder. The questionnaire elicits comments and responses from users, and the results 
component calculates the TRL likelihood distributions based on users' responses for a given process within a technology.

2.6. Click on the "TRL" folder under "File Manager", the user will be directed to the Technology Readiness Levels table where nine TR levels are listed. The text below the table indicates the specific template on which the likelihood model is based.

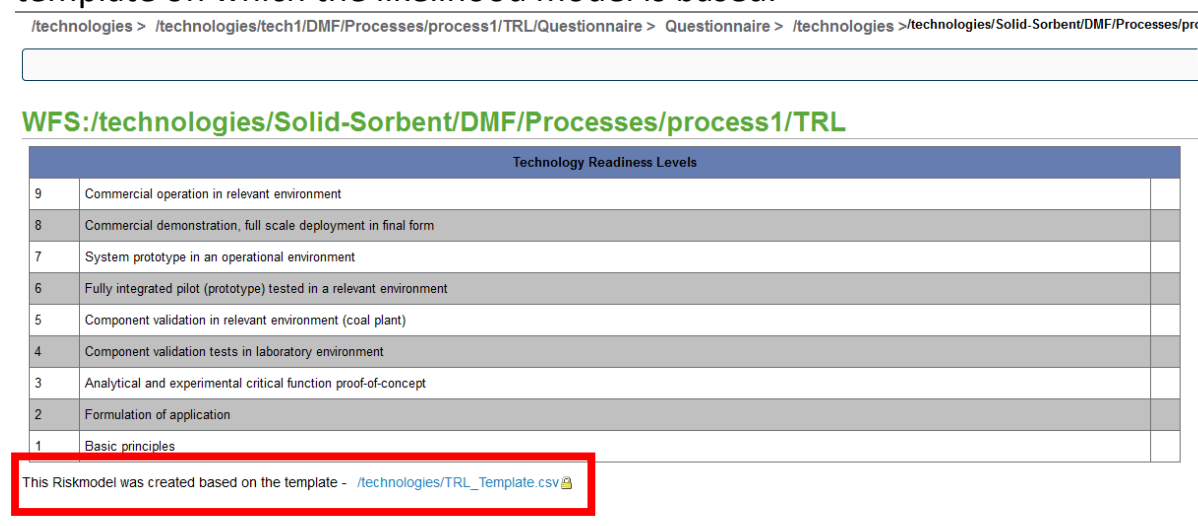

2.7. If the user wishes to modify the table, click on the "Edit With Form" button as shown in the figure above. A blank table will appear, allowing the user to enter new text that adds specific conditions for each TR level. The "Page revision log" enables the user to document changes made to the table, and to save, preview, show, or cancel the changes by clicking on one of the four tabs.

CCSI Home > UserLogin > /technologies/SolidSorbent/Processes $>$ /technologies $>$ /technologies/SolidSorbent/Processes/Adsorber/TRL

Page state: unprotected $\boldsymbol{\nabla}$

» Advanced access rights definition

\section{Edit TRL Definition: WFS:/technologies/SolidSorbent/Processes/Adsorber/TRL}

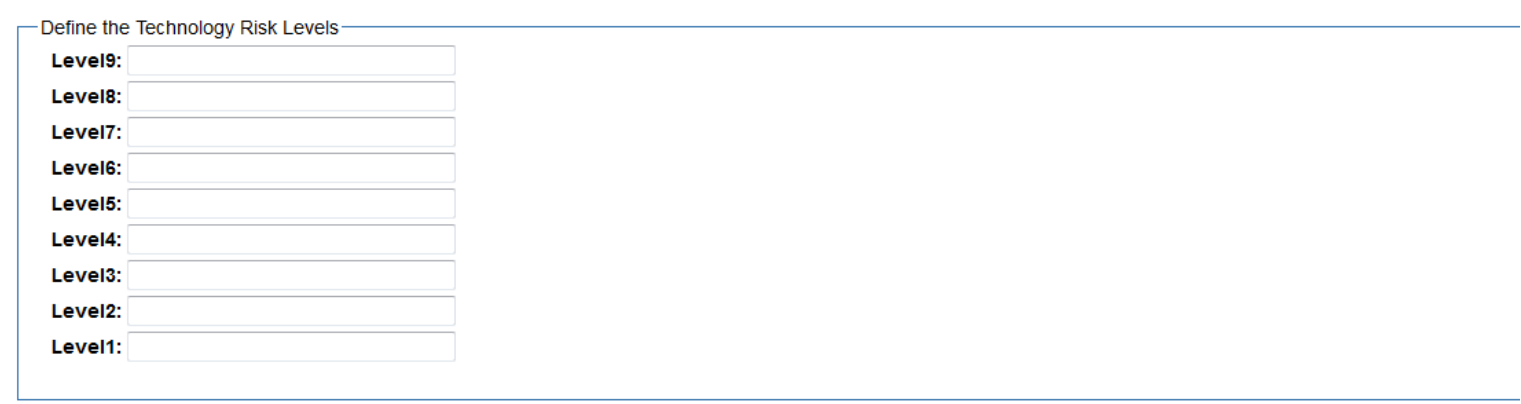

Page revision log

Summary:

This is a minor edit Watch this page

Save page Show preview Show changes Cancel

2.8. To view the TRL questionnaire, click on "Questionnaire" under "File Manager". The user will be prompted to make a selection from two options:

Do you want to

Evaluate the questionnaire?

- Submit answers?

Submit Cancel 
- Evaluate the questionnaire: allows the users to evaluate the relevance of each question, and provide comments about the questions.

- Submit answers: allows the user to respond to the Yes/No questions in the questionnaire and submits the answers. Submission will feed into the Results section to support the calculation of technology readiness level likelihood assessment.

2.9. If choosing "Evaluate the questionnaire," the user will be directed to a questionnaire page that is intended for eliciting feedback and critique about the questionnaire itself. The design of the questionnaire follows the nine levels of technology readiness illustrated in the TRL table described in Section 2.6. Under each level, a series of questions specific to that TRL are listed. At the end of each question there is a small blue icon. The user can click on the icon to open a small window and provide evaluation.

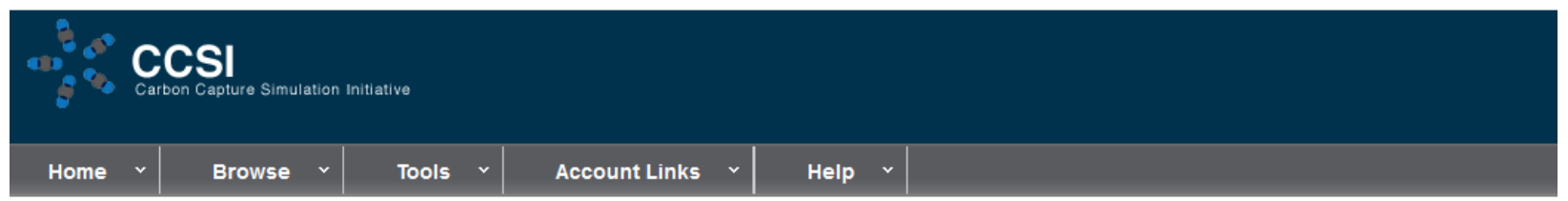

/technologies/SolidSorbent/Processes > /technologies/SolidSorbent/Processes/Adsorber > /technologies/SolidSorbent/Processes/Adsol

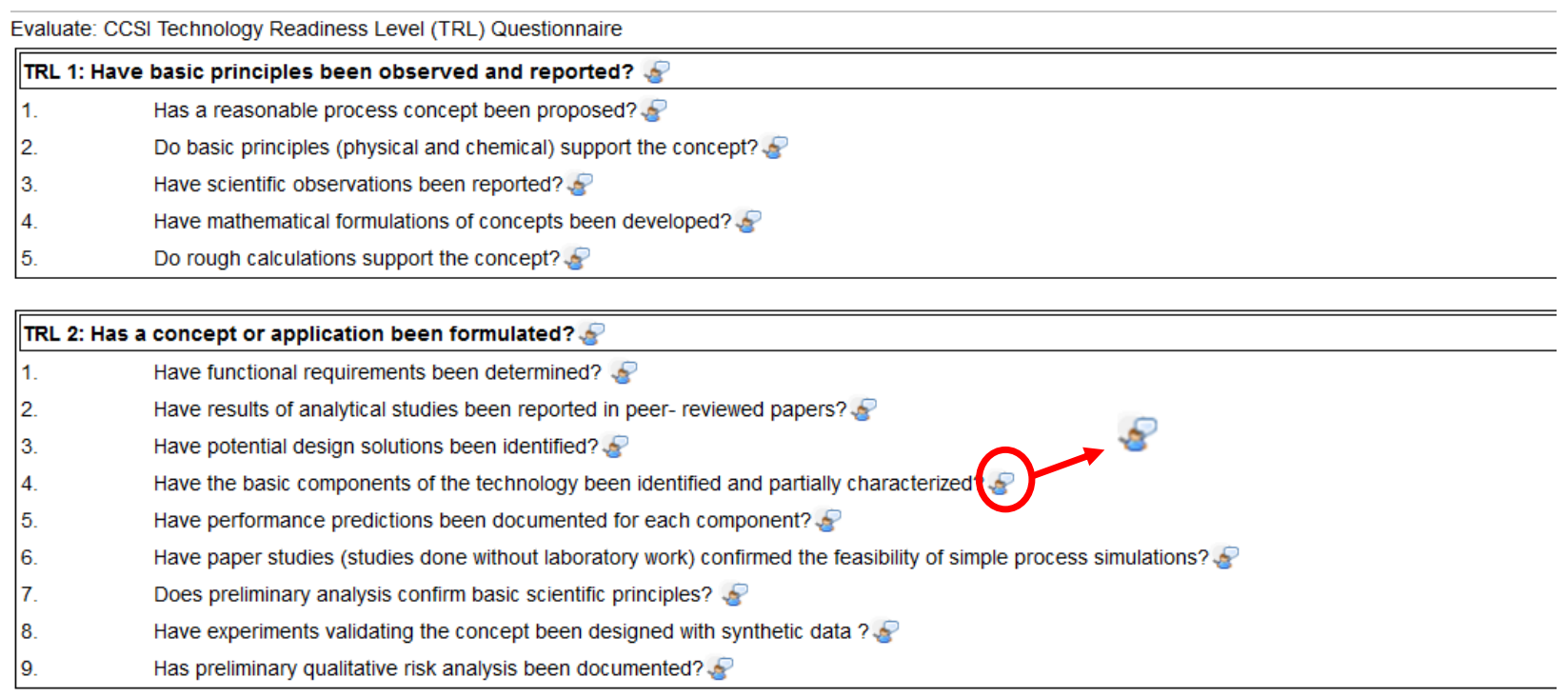

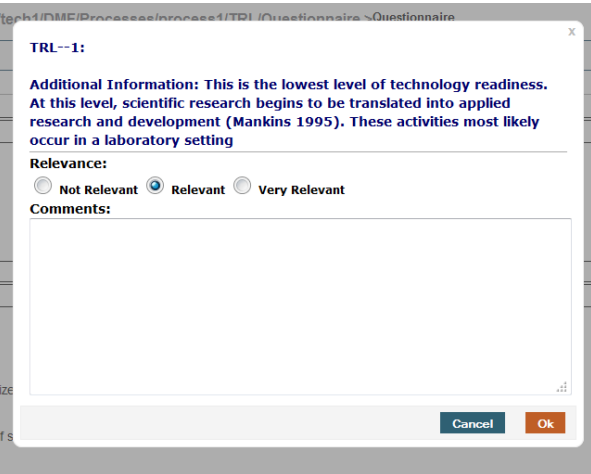

The small window asks the user to rate the relevance of each question by choosing from Not Relevant, Relevant, and Very Relevant. Wherever appropriate, the window also provides a description for each of the nine technology levels, additional information about technical terms used in the elicitation questions, and a comment box where modification suggestions can be entered. The user can save their input by clicking on the "OK" button or cancel their input by clicking on the "Cancel" button.

Upon completion of the evaluation, the user can exit the evaluation page by clicking on the "Go back one page" arrow 
in the address bar on the browser; or by locating the "bread crumbs", i.e. the directory path listed above the questionnaire (shown below) and click on the desired path segment to exit the evaluation page.

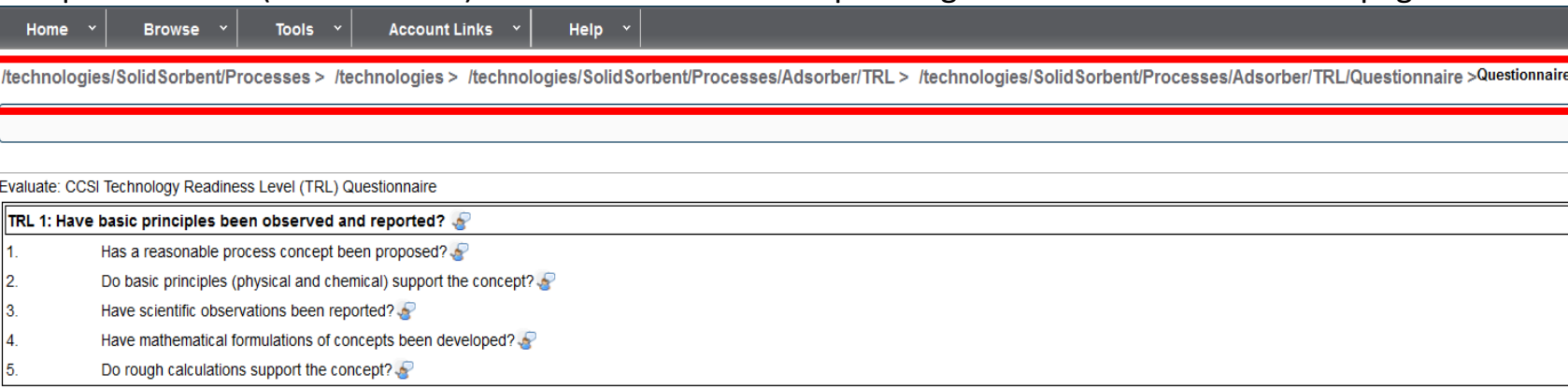

2.10. If choosing "Submit answers," the user will be directed to the questionnaire that is intended to provide input/data for the TRL likelihood model. To that end, the user will respond to the questions by clicking on the Yes/ No radio buttons at the end of each question. The blue icons similarly provide the definition for each of the nine technology readiness levels and definitions of terminology wherever needed. Users need to mouse-hover over the icon to view the information. Upon completion, the user needs to submit the responses by clicking the "Submit" button or cancel the responses by clicking on the "Cancel" button.

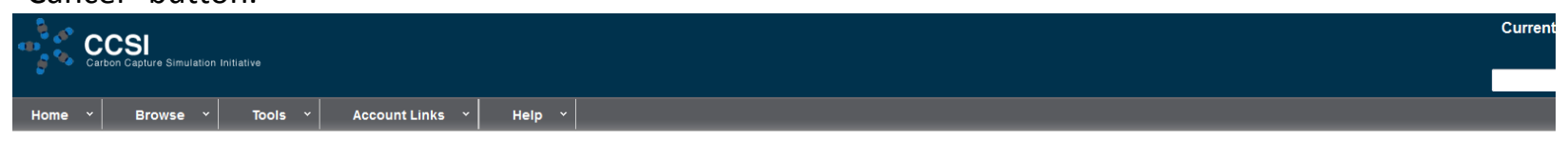

technologies/tech1/DMF/Processes/process2/TRL > /technologies > /technologies/Solid-Sorbent/DMF/Processes/Adsorber/TRL > /technologies/Solid-Sorbent/DMF/Processes/Adsorber/TRL/Questionnaire >Questionna

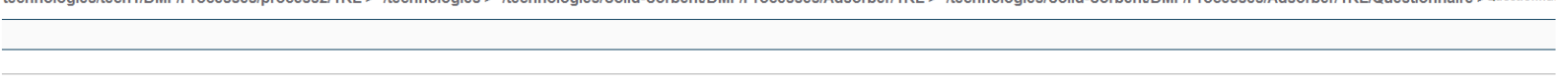

:CSI Technology Readiness Level (TRL) Questionnaire

Has a reasonable process concep beerted?

Dasic principles (physical and been proposed?

ave scientific observations been reported?

Have mathematical formulations of concepts ben

Do rough calculations support the concept?

At this level, practical applications of the characteristics

based on the basic scientific principles observed at TR

can be identified. The application is still conjectural.

TRL 2: Has a concept or application been formulated?:0 Have functional requirements been determined? [ ${ }_{2}$ conducted to support the proposed application (Mankins ave results of analytical studies been reported in

Have potential design solutions been identified?

conducter

Have the basic components of the technology been identified and partially characterized?

Have performance predictions been documented for each component?

Have paper studies (studies done without laboratory work) confirmed the feasibility of simple process simulations?

Does preliminary analysis confirm basic scientific principles?

Have experiments validating the concept been designed with synthetic data ?

Has preliminary qualitative risk analysis been documentet?

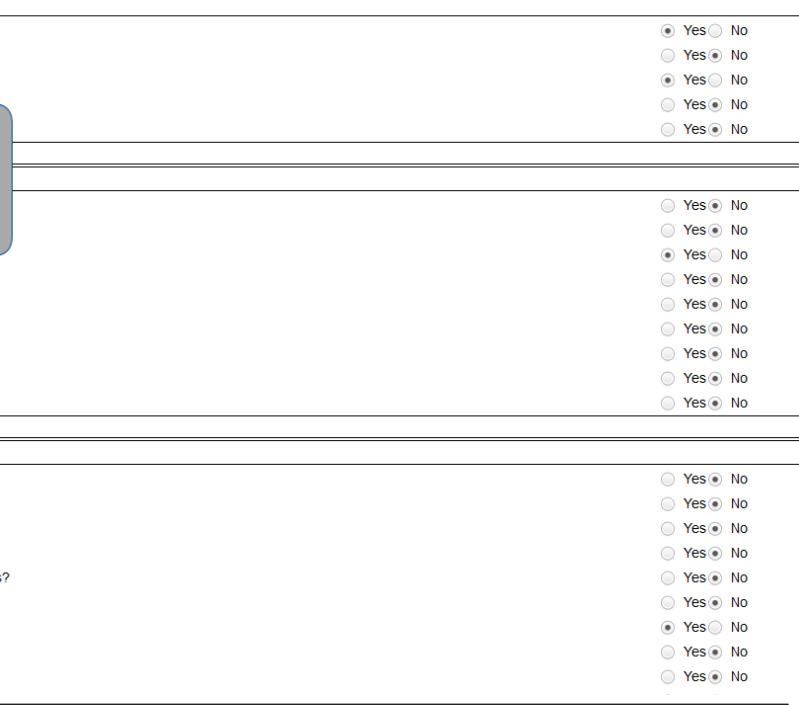

TRL 9: Has the actual unit successfully operated in the full operational environment (hot operations)? 650 MW

Does technology/system function as defined in Operational Concept document?

Has technology/system been deployed in intended operational environment?

Has technology/system been fully demonstrated?

Has Operational Test and Evaluation (OT\&E) been successfully completed and documented?

Have design to cost (DTC) goals been met?

Have safety/adverse effects issues been identified and mitigated?

Has all programmatic documentation been completed? :0

Yes $\odot$ No
Yes $\odot$ No
Yes $\odot$ No
Yes $\odot$ No
Yes $\odot$ No
Yes $\odot$ No
Yes $\odot$ No


2.11. Once submitted, the user will be directed to a new page with two options: (a) to view results collected up to that point; or (b) resubmit the questionnaire. The user can choose either option by clicking on the links provided.

\section{Special:Questionnaire}

You have successfully submitted this questionnaire. You can view results collected so far here

or You can resubmit the questionnaire here

2.12 If choosing to view the results, the user will be directed to the results page and prompted to select the parameters on which the results are computed. The parameters are grouped by technologies, processes, and statistics. Within each parameter group, the aggregate ( shown as "All") and all its constituent components are available for selection. In particular, "statistics" computes the mean (average) for all the users who have submitted responses, and for the user who is viewing the results as well as for each TRL-LM user group. In the example below, the user "Ccsiuser1" is the individual user who submitted his/her responses and is viewing the results, at the same time this user is a member of the CCSI Group. The scope of viewing privileges is based on the user's role and group membership. Since user grouping is implemented by the administrator, it is important to communicate accurate role and group membership information with your administrator when requesting/createing a new user account.

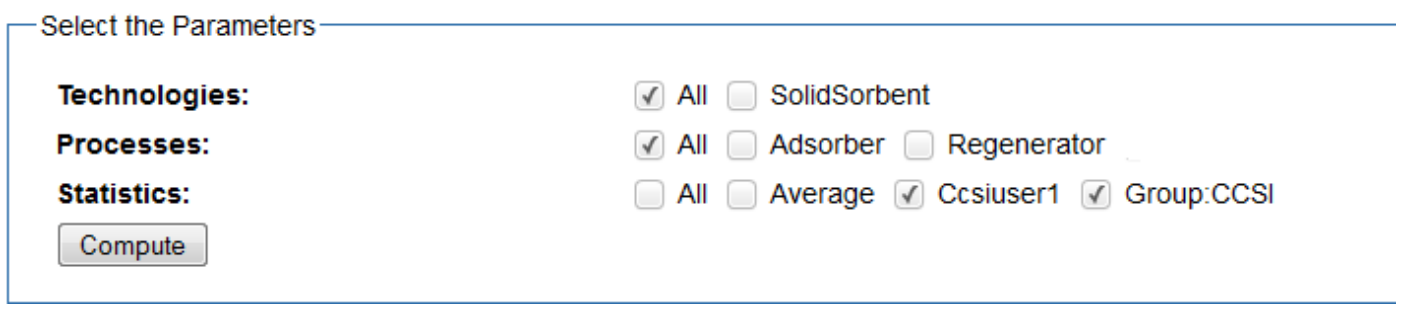

Once the appropriate parameters are chosen, click on the "Compute" button and a Technology Readiness Level diagram will be displayed. The legend represents all the chosen parameters. The X-axis represents the technology readiness level scale, ranging from 1 to 9 while the $Y$-axis is the complementary cumulative distribution function (CCDF), ranging from 0 to 1 . A corresponding probability distribuiton table is also displayed to provide numeric values captured by the digram. The table can be downloaded as a .csv file. 


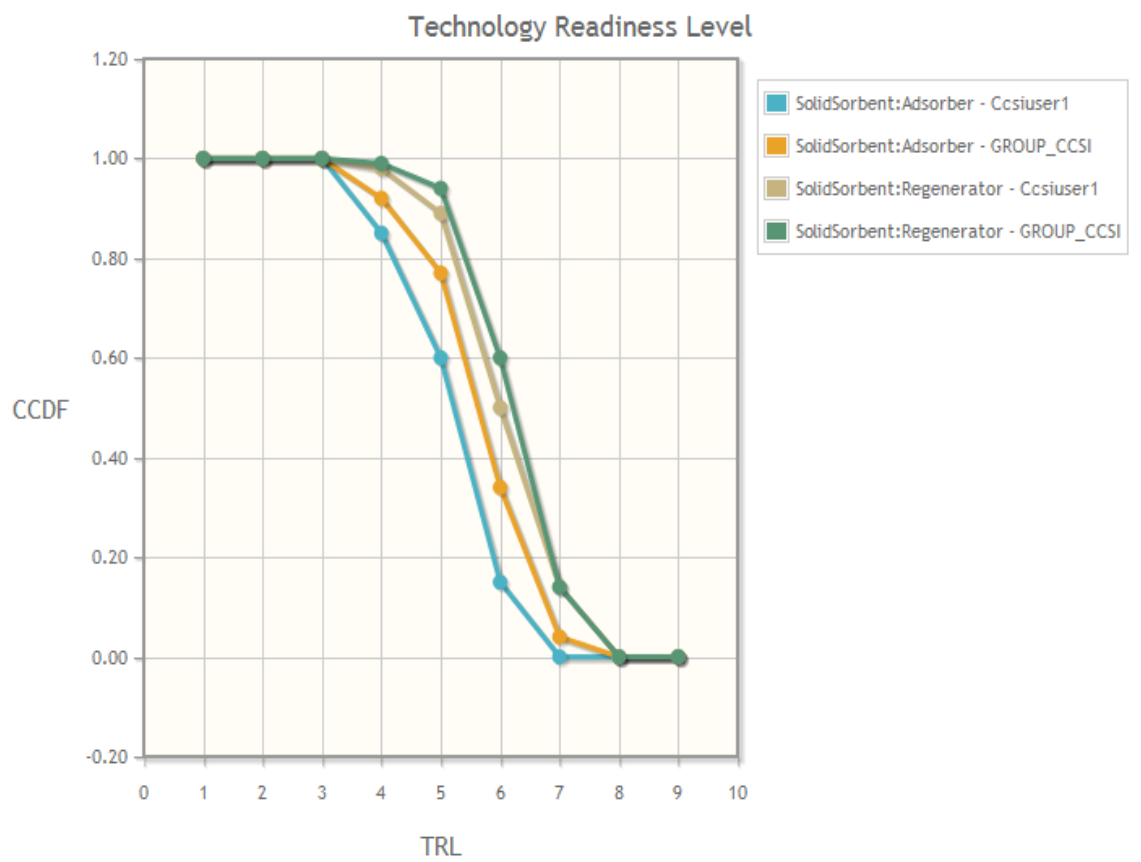

\begin{tabular}{|c|c|c|c|c|c|c|c|c|c|c|c|}
\hline \multirow[b]{2}{*}{ Technology凶 } & \multirow[b]{2}{*}{ Process》 } & \multirow[b]{2}{*}{ Statistics》 } & \multirow[b]{2}{*}{ TRL1四 } & \multirow[b]{2}{*}{ TRL2区 } & \multirow[b]{2}{*}{ TRL3区 } & \multirow[b]{2}{*}{ TRL4『 } & \multirow[b]{2}{*}{ TRL5》 } & \multirow[b]{2}{*}{ TRL6区 } & \multirow[b]{2}{*}{ TRL7凹 } & \multicolumn{2}{|c|}{ Download results as .CSV file } \\
\hline & & & & & & & & & & TRL8》 & TRL9凶 \\
\hline SolidSorbent & Adsorber & Ccsiuser1 & 1.00 & 1.00 & 1.00 & 0.85 & 0.60 & 0.15 & 0.00 & 0.00 & 0.00 \\
\hline SolidSorbent & Adsorber & GROUP_CCSI & 1.00 & 1.00 & 1.00 & 0.92 & 0.77 & 0.34 & 0.04 & 0.00 & 0.00 \\
\hline SolidSorbent & Regenerator & Ccsiuser1 & 1.00 & 1.00 & 1.00 & 0.98 & 0.89 & 0.50 & 0.14 & 0.00 & 0.00 \\
\hline SolidSorbent & Regenerator & GROUP_CCSI & 1.00 & 1.00 & 1.00 & 0.99 & 0.94 & 0.60 & 0.14 & 0.00 & 0.00 \\
\hline
\end{tabular}

\section{Customization Capabilities for Portfolio Management}

\subsection{Template Modification}

Although the questionnaire is based on the default template, TRL-LM provides template modification and upload options if the user decides to modify the current template or use a different template. To do so, the user needs to navigate back to the File Manager and click on "TRL_template.csv." The user will then be directed to a new page containing the default csv template file.

\section{WFS:/technologies/TRL Template.csv}

Back to Parent

/technologies/TRL_Template.csv署 (file size: $15 \mathrm{~KB}$, MIME type: text/csv)

Warning: This file type may contain malicious code. By executing it, your system may be compromised.

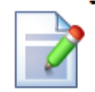

Click on the csv file name, the user will be prompted to log in again in order to save the file. Once saved, the template can be modified according to the user's preference and/or the characteristics of the specific industry/research domain of interest. 


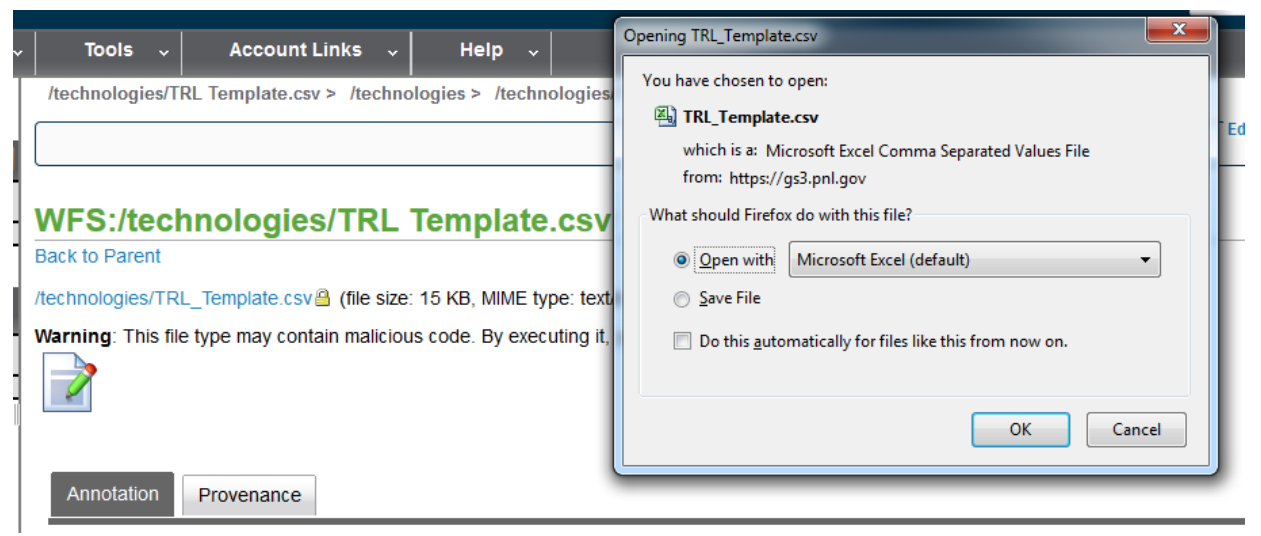

\subsection{Uploading a New Template to TRL-LM}

To upload a modified or new template to the TRL-LM interface, the user needs to navigate to the specific process where a different TRL questionnaire template is required. In the following example, we plan to add a new process to the Solid Sorbent technology, which already has two processes: Adsorber and Regenerator.

The user needs to follow the steps below to upload a template.

(1) Locate the File Manager and click on "Processes".

(2) The user will be directed to a new page displaying the two existing processes.

(3) Locate the File Manager and click on the create icon (green plus sign).

(4) A new window will appear, asking the user to specify the content of the new creation. The dropdown list provides two options: Collection and Process. Collection refers to a free-standing directory or file folder used to store any project reference documents, manual, etc. that are associated with a process.

(5) The user chooses "Process" from the drop-down list and names the process "Conveyor". The user is prompted to upload a different TRL template file by clicking "Browse" and then clicking "Create" to complete the creation command. If the user prefers to use the default template, skip the browsing step and simply clicks "Create".

(6) Once the operation is complete, the user should see "Conveyor" under the File Manager as a parallel folder to Adsorber and Regenerator. Note, by creating a new process, the TRM-LM automatically generates an associated TRL folder, a questionnaire, and a Results folder. 
1

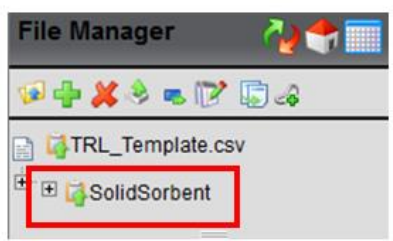

4

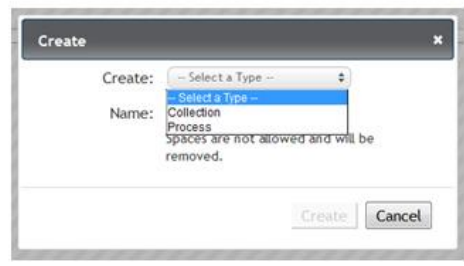

2

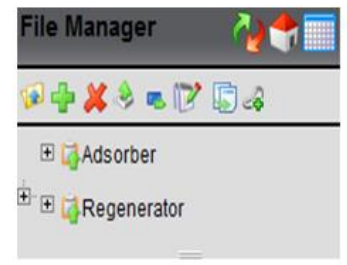

5

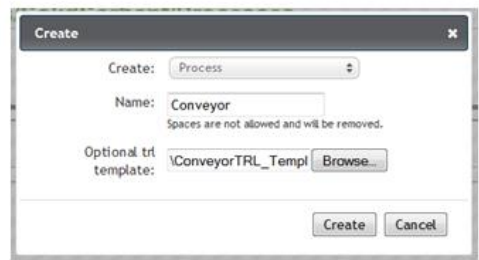

3

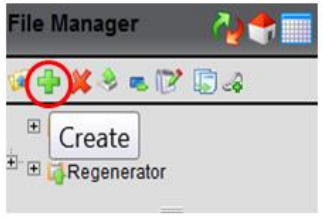

6

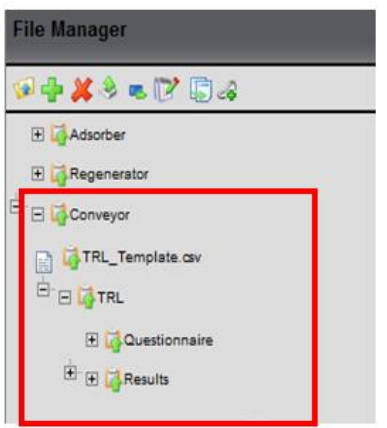

\subsection{Adding a New Technology to TRL-LM}

To add a new technology to TRL-LM, follow the procures below.

1) Navigate to the File Manager on the main page. In the example, there is one technology currently in the TRL-LM.

2) Click on the "Create" icon (green plus sign).

3) A new window will appear, prompting the user to specify what to create. The drop-down list offers two options: Creation and Technology.

4) Choose "Technology" and enter a name for the new technology. In this example, we enter "Liquid Solvent". If the user prefers to upload a different template than the default, click on the "Browse" button to retrieve and upload the template file. If using the default template, skip this step, and then click on the "Create" button to complete the process.

5) Upon completion, the new technology will be displayed under the File Manager as a parallel folder to Solid Sorbent. Notice, when creating a new technology, TRL-LM creates a new folder for the technology and automatically generates a "Processes" folder for it WITHOUT also generating an associated TRL folder, a questionnaire, and a Results folder for the new technology. To add these folders to a newly added technology, follow Section 3. 2.

6) In this example, we add a process, MEA, to the Liquid Solvent technology and fill out the TRL questionnaire for MEA. 
1

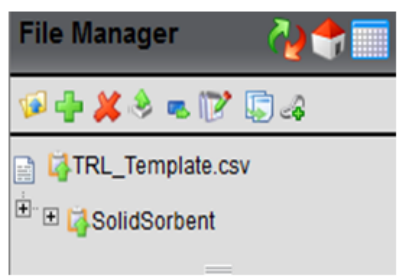

4. Add Liquid Solvent Technology

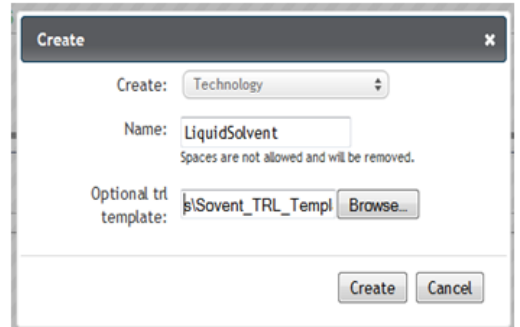

2

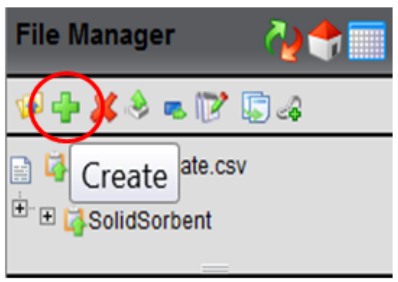

5. Add MEA to Liquid Solvent Technology

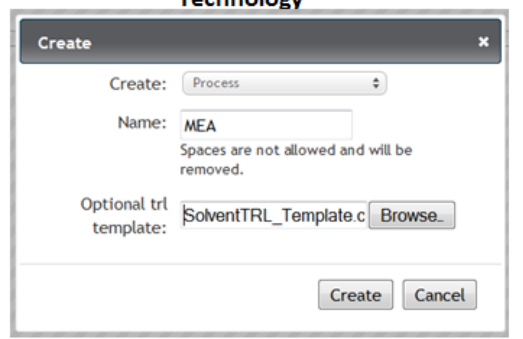

3

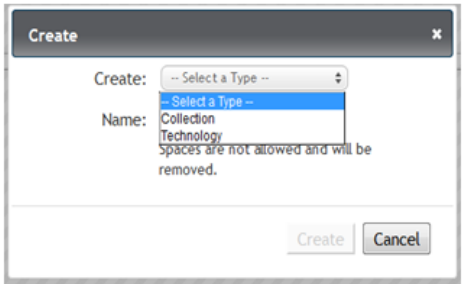

6. All Technologies and Processes

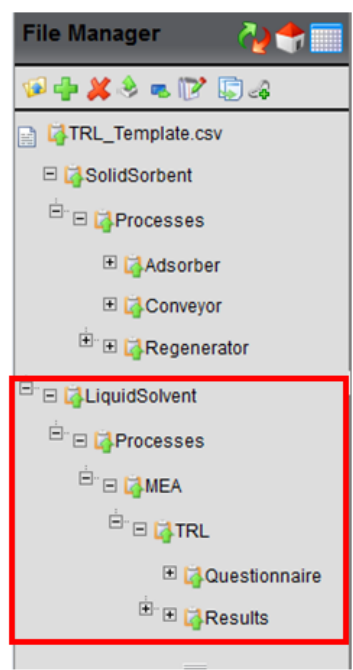

After adding new technologies and processes, users can proceed to provide answers to the questionnaires that are tailored specifically for these new additions. To review the TRL-LM results for all, go to File Manager, click on Questionnaire under TRL for any process or technology. Click "Submit Answers" to fill out the questionnaire. Then click "Submit" to submit your responses. On the new page, select "view results collected so far". On the view results page, select the appropriate parameters. Select "All" to view the results for all the technologies and processes included in the TRL-LM. As, the following figure shows, the TRL-LM diagram and the results table display every technology and process that is included in the TRL-LM. As the results demonstrate, the liquid solvent technology is relatively more mature than the solid sorbent technology. Within the solid sorbent technology, the technology readiness level varies from one process to another. 


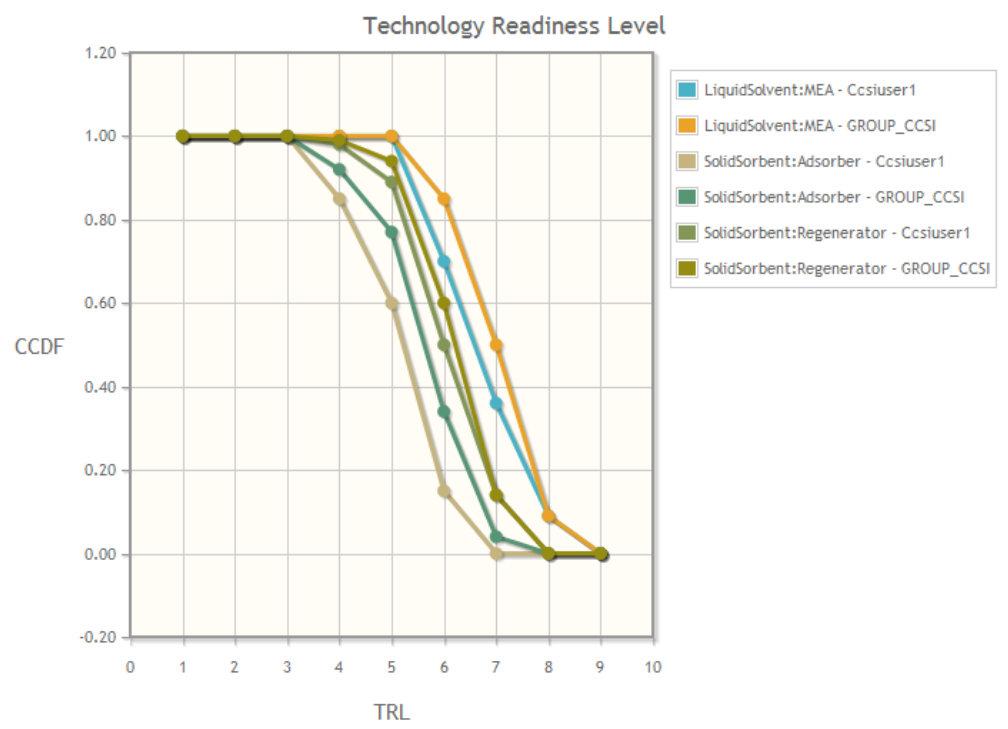

\begin{tabular}{|c|c|c|c|c|c|c|c|c|c|c|c|}
\hline \multirow[b]{2}{*}{ Technology凶 } & \multirow[b]{2}{*}{ Process } & \multirow[b]{2}{*}{ Statistics } & \multirow[b]{2}{*}{ TRL1四 } & \multirow[b]{2}{*}{ TRL2凹 } & \multirow[b]{2}{*}{ TRL3凶 } & \multirow[b]{2}{*}{ TRL4■ } & \multirow[b]{2}{*}{ TRL5凹 } & \multirow[b]{2}{*}{ TRL6 6 } & \multirow[b]{2}{*}{ TRL7凹 } & \multicolumn{2}{|c|}{ Download results as .CSV file } \\
\hline & & & & & & & & & & TRL8凹 & TRL9凹 \\
\hline LiquidSolvent & MEA & Ccsiuser1 & 1.00 & 1.00 & 1.00 & 1.00 & 1.00 & 0.70 & 0.36 & 0.09 & 0.00 \\
\hline LiquidSolvent & MEA & GROUP_CCSI & 1.00 & 1.00 & 1.00 & 1.00 & 1.00 & 0.85 & 0.50 & 0.09 & 0.00 \\
\hline SolidSorbent & Adsorber & Ccsiuser1 & 1.00 & 1.00 & 1.00 & 0.85 & 0.60 & 0.15 & 0.00 & 0.00 & 0.00 \\
\hline SolidSorbent & Adsorber & GROUP_CCSI & 1.00 & 1.00 & 1.00 & 0.92 & 0.77 & 0.34 & 0.04 & 0.00 & 0.00 \\
\hline SolidSorbent & Regenerator & Ccsiuser1 & 1.00 & 1.00 & 1.00 & 0.98 & 0.89 & 0.50 & 0.14 & 0.00 & 0.00 \\
\hline SolidSorbent & Regenerator & GROUP_CCSI & 1.00 & 1.00 & 1.00 & 0.99 & 0.94 & 0.60 & 0.14 & 0.00 & 0.00 \\
\hline
\end{tabular}

\subsection{Delete Existing Processes and Technologies}

To delete a process and its associated folder,

(1) Navigate to File Manager at the process level and click on the delete symbol (red cross).

(2) A small window will appear, asking the user to specify what to delete. Check the appropriate folder(s) (NewProcess is checked in this example), and click "Delete" to complete the deletion process.

(3) The deleted process folder is no longer listed under File Manager. 

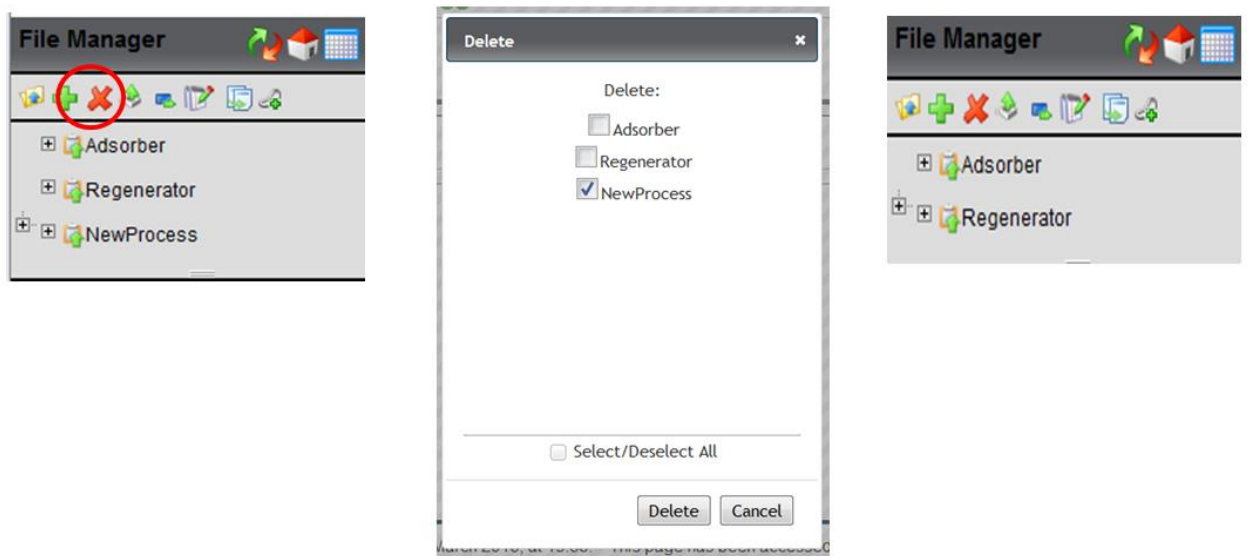

To delete a technology and its associated folders,

(1) Navigate to File Manager at the technology level and click on the delete symbol (red cross).

(2) A small window will appear, asking the user to specify what to delete. Check the appropriate folder(s)(Liquid Solvent is checked in the example), and click "Delete" to complete the deletion process.

(3) The deleted technology folder is no longer listed under File Manager. 


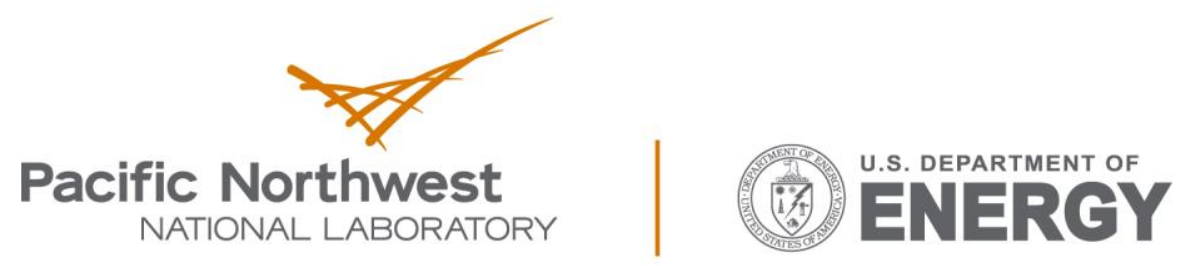

Proudly Operated by Battelle Since 1965

902 Battelle Boulevard

P.O. Box 999

Richland, WA 99352

1-888-375-PNNL (7665)

www.pnnl.gov 